\title{
The Role Of Institutional Conditions In The Impact Of Economic Growth On Poverty
}

\author{
Saeedeh Behnezhad ${ }^{1}$, Seyed Mohammad Javad Razmi ${ }^{\uparrow}$, Seyed Saeed Malek sadati ${ }^{1}$ \\ ${ }^{1}$ Faculty of Economics and Administrative Sciences, Ferdowsi University of Mashhad, Iran
}

\begin{tabular}{ll}
\hline ARTICLE INFO & ABSTRACT \\
\hline Article History & Purpose: \\
& According to the New Institutional View, the main reason for the great difference between \\
Received 9 May 2021; & countries in terms of growth, development and economic welfare is their institutional \\
Accepted 5 October 2021 & structures and foundations. Creating a stable structure in human relationships, institutions \\
\hline JEL Classifications & reduce insecurity, transaction costs and increase people's motivation. In this regard, the \\
C24 ،O40 'E02 'I32 & present study examined the role of institutional conditions in the impact of economic \\
& growth on poverty in middle and high per capita income countries from 2004 to 2017. \\
& Design/methodology/approach: \\
& This study was conducted by the panel threshold approach and the general index of good \\
& governance was used to measure the institutional quality, calculated using the weighted \\
& average of the six governance indices of the World Bank. \\
& Findings: \\
& The threshold value in this model is - 1.0583, indicating that when the good governance \\
& index crosses this threshold and the institutional quality improves, economic growth will \\
& reduce poverty to a greater extent. \\
& Research limitations/implications: \\
& In this study, we faced data limitations on poverty, and many countries did not have \\
& continuous annual data. \\
& Originality/value: \\
& To my knowledge, no study has been conducted yet on the role of institutional quality in the \\
& impact of economic growth on poverty. Therefore, this study enhances our understanding of \\
Keywords: & the importance of institutions and their effect on the relationship between economic growth \\
Economic Growth, & and poverty.
\end{tabular}

\section{Introduction}

Recession, high rate of unemployment, corruption, and other social and economic factors have left low-income households in poverty in most countries and they do not enjoy the benefits of economic growth, so in recent years the issue of poverty eradication has been considered and the support of the United Nations and its affiliates has put this issue on the agenda of governments in most countries. Hence, various studies have been conducted in different countries on how to reduce poverty, most of which have mentioned economic growth as the main solution to reduce poverty (Lyubimov, 2017).

However, there is intense debate over the extent to which the poor benefit from this growth. some economists believe that liberal economic policies should be supported to provide an opportunity to increase the income of the poor. But another group believes that the benefit of economic growth for the poor are undermined or even offset by sharp increase in inequality (Dollar and Kraay, 2002).

with the rising differences between countries in terms of economic growth and poverty, economists sought to find the reason for these differences.

In 1973, North and Thomas suggested that countries' institutional structures and foundations are one of the most important reasons for the great differences between them in terms of growth, development and economic welfare (Acemoglu et al., 2005).

Therefore, a new approach known as New Institutional Economics was introduced to the economics literature. 
According to North (1990), "institutions are the rules of the game in society; or more formally, they are humanly devised constraints that shape human interaction. Hence, they structure in human exchange, whether political, social or economic."

Institutions and the type of governance of a country are among the primary and main factors determining the incentives of individuals to invest in and acquire the skills that all these factors lead to economic success in more production, higher income, and better economic well-being in the long run. In other words, good governance means good public service, marketization, and rule of law, et al., which encourage the "helping hand" of power or inhibit the "grabbing hand" of power, resulting in good economic performance (Liu et al., 2018). North (1990) believed that Institutional quality limits corruption and inefficiency in government bureaucracy since good and stable institutions encourage more private investment (Assadzadeh \& Pourqoly, 2013). Keefer and Knack (1997) argued that poor institutional quality undermines the security of property rights (Perera and Lee, 2013). Moreover, poor institutions allow and encourage unproductive activities which can slow down economic growth as resources are driven away from the most productive activities (Dhrifi, 2013). Dellepiane-Avellaneda (2010) maintained that more strictly follow certain rules of good governance, can develop faster, and use available resources more efficiently to help the most vulnerable in the society (Jindra \& Vaz, 2019).

In this regard, the present study aimed to determine the effect of the institutional condition on the relationship between economic growth and poverty. Also, as part of this research, we have tried to contribute to solving the fundamental question: a better institutional condition will improve the effect of economic growth on poverty reduction?

It is important to note that one of the limitations we face in this research, is the lack of poverty data which makes our sample and time period smaller. According to data limitation, 53 middle and high per capita income countries were studied from 2004 to 2017 using econometric models. The names of these countries are given in Table 1.

Table 1: List of countries

\begin{tabular}{|l|l|}
\hline \multirow{2}{*}{ High- income economies } & $\begin{array}{l}\text { Austria, Belgium, Cyprus, Czech Republic, Denmark, } \\
\text { Estonia, Finland, France, Germany, Greece, Hungary, }\end{array}$ \\
& $\begin{array}{l}\text { Ireland, Italy, Latvia, Lithuania, Luxembourg, Malta, } \\
\text { Netherlands, Norway, Panama, Poland, Portugal, } \\
\text { Romania, Slovakia, Slovenia, Spain, Sweden, Switzerland, } \\
\text { Uruguay }\end{array}$ \\
\hline Upper- middle-income economies & $\begin{array}{l}\text { Argentina, Armenia, Belarus, Brazil, Bulgaria, Colombia, } \\
\text { Costa Rica, Dominican Republic, Ecuador, Georgia, }\end{array}$ \\
& $\begin{array}{l}\text { Indonesia, Iran, Kazakhstan, Paraguay, Peru, Russia, } \\
\text { Thailand, Turkey }\end{array}$ \\
\hline \multirow{2}{*}{ lower-middle-income economies } & $\begin{array}{l}\text { Bolivia, El Salvador, Honduras, Kyrgyzstan, Moldova, } \\
\text { Ukraine }\end{array}$ \\
\hline
\end{tabular}

This section reviews the research design and the second section explains the research background. Then, in the third section, the research method and the proposed model are presented. The fourth and fifth sections also include model estimation and the analysis of results, summary, and research suggestions, respectively.

\section{Review of Literature}

\subsection{Theoretical Review}

In recent decades, many economists have come to believe that low economic growth rates are the reason for the spread of poverty, stating that higher growth could solve the problem of unemployment and poverty. During these years, no attention was paid to how the benefits of growth were distributed, and development was considered equivalent to increasing national production. Hence, much research has been conducted on the relationship between growth and poverty, in which economists have sought to answer the question of whether the main effect of growth and its benefits go to the poor or the most of its benefits are absorbed by the rich and low-income people benefit to a lesser extent? Based on these studies, in analyzing the relationship between economic growth and poverty, three concepts have been developed, including Trickle-Down Growth, Immiserizing Growth, and Pro-Poor Growth.

In Trickle-Down Growth, the benefits of economic growth are gradually and indirectly transferred from the rich to the poor, so that, first, the rich enjoy the benefits of growth and then by spending money, the poor also benefit. In this case, although economic growth reduces poverty, the benefits of the poor are less than those of the rich, and economic growth will lead to increased inequality (Kakwani and Pernia, 2000).

Immiserizing Growth was suggested by Bhagwati (1988) in the context of the Green Revolution and states that economic growth increases poverty. In this case, income inequality increases so much that it offsets the effect of poverty reduction (ibid.).

In Pro-Poor Growth, definitions are divided into two categories. One group pays attention to changes in inequality along with economic growth, but the other group considers economic growth only to refer to the term pro-poor (Kraay, 2006).

Thus, as growth theories could not explain the low and unsustainable economic growth of poor countries and there are different and sometimes contradictory theories about the impact of economic growth on poverty, 
institutional and political approach to growth and development was raised after the second half of the twentieth century. According to this theory, capital accumulation, innovation, education, etc. are among the superficial reasons for growth and institutions are the main or fundamental factors in the growth and development of countries (Acemoglu et al., 2005). New institutional economists believed that improving indicators of good governance is a necessary condition for creating the institutional conditions of lowering transaction costs and thus a competitive market is conducive to increasing the efficiency in the allocation of resources and the pace of economic growth (Mira \& Hammadache, 2017).

Institutions not only affect economic performance but also play a significant role in determining the consequences of growth and poverty. According to Tebaldi and Mohan (2010), institutional quality affects the level of poverty through market inefficiency and misallocation of resources. Efficient governments are more successful at providing basic services and access to public goods, thereby improving well-being and increasing social equity (Jindra \& Vaz, 2019). Conversely, inefficient institutions and poor governance cause public resources to be spent in the interests of the rich, ignoring the needs of lower-income deciles such as health, education, skills, and, consequently, finding a suitable job. Hence, unemployment increases in this group and leads to the aggravation of poverty. In summary, the relationship between institutions, economic growth, and poverty can be shown as follows:

Figure 1: Relationship between institutions, economic growth and poverty

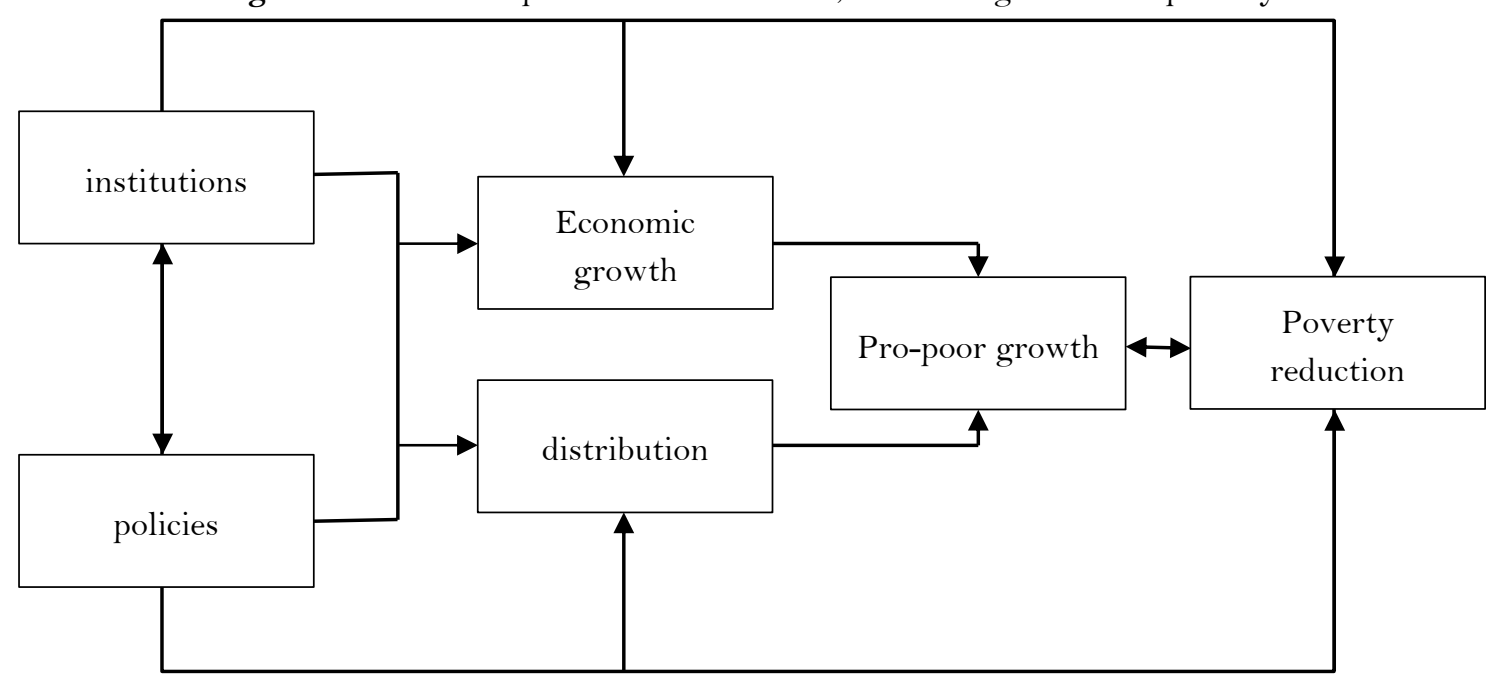

Adapted from Asian Development Bank (2002)

As shown, institutions affect poverty both directly and indirectly through economic growth and income distribution (Asian Development Bank, 2002).

In general, to achieve the benefits of economic growth and meet the challenges of development, countries need institutional structures that support the market economy, and this requires two types of institutions: (1) Institutions that foster exchanges through building trust and reducing transaction costs. (2) Institutions that influence the state to protect private property rights (Shirley, 2008).

\subsection{Previous studies}

Numerous empirical studies on institutions and their impact on economic growth have been conducted using various institutional indicators and in all of them, it has been stated that the reason for the difference in capital accumulation, productivity, and as a result, production per capita among countries fundamentally depends on differences in country's economic and institutional infrastructure. Institutions and government policies determine the economic environment within which individuals accumulate skill, and firms accumulate capital and produce output (Barro, 1991; Knack and Keefer, 1995; Hall and Jones, 1999; Kaufmann and Kraay, 2002; Easterly and Levine,2003; Assane and Grammy, 2003; Acemoglu et al., 2005; Nsiah and Fayissa (2010), Tariq et al., 2016; Huang and Ho, 2017; Almeida, 2020).

On the other hand, some studies have attempted to find the relationship between institutional quality and poverty. In 2010, Tebaldi and Mohan using eight institutional variables and the instrumental variable method examined the impact of institutions on poverty, they showed that the economy, with a robust system to control corruption, an effective government, and a stable political system improves economic growth and reduces poverty. Corruption, ineffective government, and political instability not only damage income distribution through market inefficiency but also increase poverty by increasing income inequality. Later, Perera and Lee (2013) showed that although improvements in government stability and law and order are found to reduce poverty, improvements in the level of corruption, democratic accountability, and bureaucratic quality appear to increase income inequality and poverty levels. Cuestas and Intartaglia (2016) asserted that better institutional quality reduces poverty in cross-section 
analysis. In another paper, Siddique et al. (2016) examined the relationship between governance and poverty alleviation. They claimed that institutions, directly and indirectly, affect poverty and education. Jindra and Vaz (2019) had also stated that although good governance can reduce multidimensional poverty, institutional reform alone may not have the desired results for all countries.

In summary, most studies emphasize the positive role of institutional quality in economic performance and state that better institutional conditions improve economic growth and reduce poverty by providing a conducive environment for economic activities. It should be noted, however, no study has been conducted yet on the role of institutions in the relationship between economic growth and poverty.

\section{Methodology}

Since threshold models are used to investigate the nonlinear and asymmetric behaviour of independent variables on the dependent variable, in this study, the panel threshold econometric model was used.

The threshold regression method was developed by Hansen (1999) for non-dynamic panels with individual fixed effects.

The structure of this model is such that each observation can be divided according to the value of an observed variable called the threshold variable. The structural form of this model is as follows:

$\mathrm{Y}_{\mathrm{it}}=\mu_{\mathrm{i}}+\beta_{1}^{\prime} \mathrm{x}_{\mathrm{it}} \mathrm{I}\left(\mathrm{q}_{\mathrm{it}} \leq \gamma\right)+\beta_{2}^{\prime} \mathrm{x}_{\mathrm{it}} \mathrm{I}\left(\mathrm{q}_{\mathrm{it}}>\gamma\right)+\mathrm{e}_{\mathrm{it}}$

In this equation, $i$ represents the individual and the subscript $t$ represents time, $\mathrm{y}$ is the dependent variable, $\mathrm{x}$ is the column vector of explanatory variables. Here $q_{i t}$ is the threshold variable, $\gamma$ is the threshold value and I(.) is the indicator function and the observations are divided into two regimes based on whether the threshold variable $\left(q_{i t}\right)$ is less or more than the threshold value $(\gamma)$. These regimes are characterized by differences in regression slopes $\beta_{1}$ and $\beta_{2}$. It should be noted that the elements $x_{i t}$ should not be time-invariant to identify $\beta_{1}$ and $\beta_{2}$. It is also assumed that the threshold variable is also not time-invariant. For error term $e_{i t}$, it is also assumed that it is independent and identically distributed (iid) with mean zero and finite variance $\sigma^{2}$.

An alternative intuitive way of writing (1) is

$y_{i t}=\left\{\begin{array}{ll}\mu_{i t}+\beta_{1}^{\prime} x_{i t}+e_{i t}, & q_{i t} \leq \gamma \\ \mu_{i t}+\beta_{1}^{\prime} x_{i t}+e_{i t}, & q_{i t}>\gamma\end{array}\right\}$

Another compact representation of (1) is to set

$x_{i t}(\gamma)=\left(\begin{array}{l}x_{i t} I\left(q_{i t} \leq \gamma\right. \\ x_{i t} I\left(q_{i t}>\gamma\right.\end{array}\right)$

And $\beta=\left(\beta_{1}^{\prime} \beta_{2}^{\prime}\right)^{\prime}$ so that (1) equals

$y_{i t}=\mu_{i}+\beta^{\prime} x_{i t}(\gamma)+e_{i t}$

What is important in this model is to estimate the value of $\gamma$, so that observations can be divided accordingly. For this purpose, Chan (1993) and Hansen (1999) proposed the least- squares method. This method is possible by minimizing the sum of squared errors. Hence, the estimation of $\gamma$ will be as follows:

$\hat{\gamma}=\arg _{\gamma} \min S_{1}(\gamma)$

It is undesirable for a threshold $\hat{\gamma}$ to be selected which sorts too few observations into one or the other regime. This possibility can be excluded by restricting the search in (3) to values of $\gamma$ such that a minimum percentage of the observation (say, $1 \%$ or $5 \%$ ) lie in each regime.

Once $\hat{\gamma}$ is obtained, the slope coefficient estimate is $\hat{\beta}=\hat{\beta}(\hat{\gamma})$. The residual vector is $\hat{e}^{*}=\hat{e}^{*}(\hat{\gamma})$ and residual variance $\hat{\sigma}^{2}=\frac{1}{n(T-1)} \hat{e}^{* \prime} \hat{e}^{*}=\frac{1}{n(T-1)} S_{1}(\hat{\gamma})$.

When the threshold value is determined, the significance of the threshold should be statistically examined. At this stage, it should be tested whether the coefficients $\beta_{1}$ and $\beta_{2}$ are significantly different from each other or not. The statistic used in this case is $\mathrm{F}$ statistic:

$\mathrm{F}_{1}=\frac{\mathrm{S}_{0}-\mathrm{S}_{1}(\gamma)}{\widehat{\sigma}^{2}}$

Where $S_{0}=\tilde{e}^{* \prime} \tilde{e}^{*}$ is the sum of squared errors. The distribution of $F_{1}$ is nonstandard and depends on the moments of the sample (Hansen,1996). As a result, it is not possible to calculate its critical values in a general form. Hansen (1999) suggests using the below bootstrap procedure for examining the significance of $F_{1}$ : (1) by minimizing the sum of squared residuals, the threshold value, and the corresponding coefficients are estimated; (2) a new sample, with the residuals of the first stage, is generated under the supposition of the null hypothesis (the explanatory variables are supposed to be nonstochastic, so they do not change). With this sample, the coefficients and residuals are estimated under the null and alternative hypotheses. Then, the simulated $F_{1}$ statistic is calculated, and (3) the above calculations are repeated many times. Using the simulated $F_{1}$ critical values of $F$ and bootstrap $p$-value will be calculated. Finally, a $p$-value is a percentage that the simulated $F_{1}$ exceeds the actual value. This will be the estimation of asymptotic $p$ value under $H_{0}$. Now, if this percentage is lower than the considered significance level (i.e. $5 \%$ ), the null hypothesis will be rejected (Hajamini, 2014).

While there is a threshold, rejecting the null hypothesis $H_{0}: \beta_{1}=\beta_{2}$, Hansen (1999) indicated That $\hat{\gamma}$ would be a consistent estimation of the true threshold $(\gamma)$, but its asymptotic distribution will be nonstandard. He suggested using the likelihood ratio for constructing the confidence interval. The null hypothesis for the true threshold test will be $H_{0}: \gamma_{1}=\gamma_{2}$, so the likelihood ratio would be in the form below 
$L R_{1}(\gamma)=\frac{\left(S_{1}(\gamma)-S_{1}(\widehat{\gamma})\right)}{\widehat{\sigma}^{2}}$

The probability of rejecting the null hypothesis increases with the value of this statistic. Hansen (1999) showed that under some assumptions, this statistic converges in distribution to the random variable $\xi$ which have the probability distribution of $P(\xi \leq x)=(1-\exp (-x / 2))^{2}$ and its reverse distribution is $c(\alpha)=-2 \log (1-\sqrt{1-\alpha})$. This function can be used to estimate the critical values. Provided that $L R_{1} \leq c(\alpha)$, the confidence interval $(1-\alpha) \%$ will be made for the sum of squared residuals and consequently the threshold.

It should be noted that the hypothesis $H_{0}: \beta_{1}=\beta_{2}$ is different from the hypothesis $H_{0}: \gamma_{1}=\gamma_{2}$. The $F_{1}$ statistic is used to test the presence of the threshold, while the $L R_{1}$ statistic is used for constructing the confidence interval of the present threshold (Hajamini, 2014).

If the existence of the first threshold is statistically confirmed, the model should be estimated by two and/or three thresholds and the significance of the thresholds should also be tested (Hansen, 1999).

\subsection{Analytical model and data}

It seems that the large differences in the nature and performance of institutions in different countries are one of the most important reasons for the difference in the rate of economic growth and its impact on poverty. Therefore, the main issue of this research is how economic growth affects poverty in different institutional conditions. Since threshold models are used to investigate the nonlinear and asymmetric behavior of independent variables on the dependent variable, in this study, the threshold panel econometric model was used to show different institutional conditions (Hansen, 1999). According to the theoretical foundations, the following equation was developed to answer the question.

$\mathrm{PH}_{\mathrm{it}}=\mu_{\mathrm{i}}+\alpha_{1} \mathrm{INF}_{\mathrm{it}}+\alpha_{2} \mathrm{POP}_{\mathrm{it}}+\alpha_{3} \mathrm{HC}_{\mathrm{it}}+\alpha_{4} \mathrm{FDI}_{\mathrm{it}}+\alpha_{5}$ LOGGDPpercapita $_{\mathrm{i}, \mathrm{t}} * \mathrm{I}\left(\mathrm{INS}_{\mathrm{i}, \mathrm{t}} \leq \gamma\right)+$ $\alpha_{6}$ LOGGDPpercapita $_{\mathrm{i}, \mathrm{t}} * \mathrm{I}\left(\mathrm{INS}_{\mathrm{i}, \mathrm{t}}>\gamma\right)+\varepsilon_{\mathrm{it}}$

In this study, the poverty headcount index was used to measure poverty. According to the World Bank's definition, poverty headcount is "the percentage of the population whose income is below the poverty line". Poverty index data were collected from the World Bank's database from 2004 to 2017 and the poverty index was considered $\$ 3.20$ per day according to the poverty line. Institutional quality, which is considered as a threshold variable, was obtained based on the principal component analysis method to calculate the weighted mean of six indicators of good governance (voice and accountability, political stability and absence of violence, government effectiveness, regulatory quality, rule of law and control of corruption) provided by the World Bank. It should be noted that each of the six governance indicators is in the range of -2.5 to +2.5 , which a higher value means a more desirable result for that country. To measure economic growth, which is considered a regime-dependent variable, the logarithm of gross domestic product per capita (at constant 2010 prices in US dollar) was employed. Control variables, including inflation rate, population growth rate, and foreign direct investment were obtained from the World Bank's website and human capital variables were obtained from the University of Pennsylvania's website.

\section{Results}

Before estimating the model, Hausman (1987) test was used to determine the fixed and random effects. The null hypothesis in this model states that there is no correlation between the individual effects and the explanatory variables. According to the results in Table 2, the null hypothesis of orthogonality is rejected, and thus the existence of fixed effects is confirmed.

Table 2: Hausman test

\begin{tabular}{ll}
\hline Chi-Square Statistic & P-Value \\
\hline 307.31 & 0.00 \\
\hline
\end{tabular}

Source: Research Data

For model estimation, we use xthreg command in Stata.

In this model, first, the threshold value is estimated by the ordinary least squares method, then the result of the threshold significance test is presented to ensure the validity of the econometric method of panel threshold. The results of these tests are presented in the following tables:

Table 3: Threshold significance test results

\begin{tabular}{ccccc}
\hline Hypothesis testing & F-stat & P-value & $\begin{array}{l}\text { Critical values } \\
\mathbf{1 0 \%}\end{array}$ & $\begin{array}{l}\text { at } \\
\text { Critical values at }\end{array}$ \\
\hline $\mathbf{H}_{\mathbf{0}}$ : No threshold & 62.11 & 0.01 & 42.84 & 53.66 \\
$\mathbf{H}_{\mathbf{1}}$ : One threshold & & & & \\
\hline
\end{tabular}




\begin{tabular}{|c|c|c|c|c|}
\hline $\begin{array}{l}H_{0}: \text { One threshold } \\
H_{1}: \text { Two threshold }\end{array}$ & 37.37 & 0.11 & 41.01 & 51.07 \\
\hline
\end{tabular}

Source: Research Data

According to the results of this test, the existence of the first threshold is statistically confirmed (it is significant at the level of $5 \%$ ), but according to the bootstrap P-Value in the second case (0.11), the existence of the second threshold cannot be accepted. The threshold value and the confidence interval are shown in the following table.

Table 4: Threshold values and confidence interval

\begin{tabular}{lcc}
\hline Model & Threshold Value & $\mathbf{9 5 \%}$ Confidence Interval \\
\hline Model with one threshold & -1.0583 & {$[-1.0734,-1.0571]$} \\
\hline Source: Research Data & &
\end{tabular}

The threshold value in this model is -1.0583 , meaning that when the good governance reaches this point, the function breaks and the coefficient of economic growth will change. According to the table above, the $95 \%$ confidence interval for the first threshold is $[-1.0734,-1.0571]$. To construct this confidence interval, the likelihood ratio is estimated for different threshold values under the null hypothesis $\mathrm{H}_{0}$ : INS $=\mathrm{INS}_{0}$, then the threshold values with a likelihood ratio of less than or equal to $\mathrm{C}(\alpha)(\operatorname{LR} 1(\gamma) \leq \mathrm{C}(\alpha))$ are then considered as confidence intervals (Hansen, 1999).

After confirming the existence of threshold and determining the number of thresholds, the results of model estimation were obtained, which are presented in the table below. In this model, the weighted mean of six indicators of good governance was used as the threshold variable to investigate the role of institutional conditions in the impact of economic growth on poverty.

Table 5: Model estimation results

\begin{tabular}{lllll}
\hline & Coefficient & P-Value & Std. error & t statistic \\
\hline LOGGDP(INS $\leq-\mathbf{1 . 0 5 8 3})$ & -50.41 & 0.00 & 8.11 & -6.21 \\
LOGGDP(INS>-1.0583) & -51.89 & 0.00 & 8.13 & -6.38 \\
INF & 0.004 & 0.88 & 0.03 & 0.15 \\
POP & 1.003 & 0.01 & 0.38 & 2.58 \\
HC & -3.63 & 0.32 & 3.67 & -0.99 \\
FDI & -0.005 & 0.00 & 0.002 & -2.74 \\
Constant & 228.91 & 0.00 & 29.69 & 7.71 \\
\hline
\end{tabular}

Source: Research Data

As seen, the economic growth coefficient before and after the threshold is different and significant. The estimation results indicate that there is a significant negative relationship (at the level of $5 \%$ ) between economic growth and poverty in the two regimes. In the first regime, the effect of economic growth on the poverty headcount is estimated to be -50.41 . But with the improvement of the good governance index and cross the threshold (-1.0583), the coefficient increases. In fact, in this case, the impact of economic growth on the poverty headcount is -51.89 . Regarding the negative coefficient of economic growth, this variable reduces poverty by creating opportunities to meet basic needs and earn more money for the poor, which also confirms the theory of pro-poor growth. According to this definition, pro-poor growth occurs when economic growth reduces poverty. In this definition, no attention is paid to changes in income inequality. On the other hand, institutions are said to be the fundamental determinants of economic growth and development of societies, which not only determine integrated economic growth but also determine the outputs of the economy, such as distribution of resources in the future (such as the distribution of wealth, physical or human capital) (Acemoglu et al., 2005). In other words, institutions not only determine the size of the aggregate pie but also determine how this pie is divided among different groups and individuals in society (ibid). Low institutional quality affects economic growth and poverty through market inefficiency and misallocation of resources (Tebaldi and Mohan, 2010). Governments can also help increase production and investment, employment, and reduce unemployment, and thus reduce poverty by improving governance indicators. As a result, good governance is essential to reducing poverty. As seen in this model with the improvement of institutional quality and regime change, the impact of economic growth on poverty also increases, meaning that if the institutional quality exceeds the threshold of -1.0583, through increasing participation of people in economic activities, reducing corruption, political stability, government efficiency, and effectiveness, and optimized resource allocation prepare the condition for improving economic growth and its outcomes, such as poverty reduction.

Reducing the purchasing power of the poor, inflation increases income inequality and poverty (Law and Soon, 2020), but in this model, inflation has no significant effect on poverty.

In the estimated regression, the population growth coefficient is 1.003. Assuming the stability of other variables, a one percent increase in population growth increases poverty by 1.003 percent. Some believe that one of the reasons for structural unemployment is population growth, so population growth and consequent unemployment will worsen the situation of the poor. On the other hand, population growth has been recognized as one of the major and most 
effective factors in reducing per capita income and consequently reducing the standard of living and public welfare (Ahlburg, 1996).

Although it is expected that by increasing human capital and increasing the capabilities of individuals, they will have the opportunity to find better jobs with higher incomes and poverty will reduce, the insignificant coefficient of this variable is not far from expected, as governments pay more attention to providing conditions for increasing education and have neglected to create jobs for educated people. Therefore, these countries have not been successful in using the benefits of increased education to reduce poverty.

Many economists believe that foreign direct investment with a positive impact on growth and development and through job creation leads to increased income of people and reduced poverty, but in this model the coefficient of this variable is very small. Assuming other conditions are stable, a one percent increase in foreign direct investment will reduce poverty by 0.005 percent.

\section{Conclusion}

Good governance is very important for economic performance, it will enable the economy to grow more and reduce poverty. In this paper, the role of institutional quality in the impact of economic growth on poverty was studied in the form of a panel threshold econometric model from 2004 to 2017. The results indicate the positive role of institutional quality in the impact of economic growth on poverty. In this model, the threshold value is set at -1.0583 . The results show that when the good governance index crosses this threshold and the institutional quality improves, the impact of economic growth on poverty also increases, meaning that at a better quality of institutions, economic growth reduces poverty to a greater extent.

These results confirm theories about the fundamental role of institutions in economic growth and development

and their consequences. Also, these results are in line with the ideas of Tebaldi and Mohan (2010) and Acemoglu et al., (2005). According to these studies, institutions pave the way for economic growth and its consequences, such as poverty reduction by creating a suitable environment for people to participate more in economic, social, and political activities, reducing corruption, political stability, government efficiency, and effectiveness and optimal resource allocation. In addition, when there are effective economic, social and political institutions, it can be expected that the development of technology, introduced in endogenous growth theories as to the engine of economic growth, will improve economic growth. Furthermore, governments can increase investment and production, as well as increase employment and reduce unemployment by improving governance indicators, thereby helping to reduce poverty.

The results and lessons above lead to some policy implications: Firstly, governance quality should be improved continuously to promote economic performance and poverty reduction programs. On the other hand, more attention should be paid to the weak aspects of governance and try to do governance reforms.

In the present study, due to the existing limitations, the focus is on cross-country analysis, but it seems that future research should study every country separately and consider the effect of every component of good governance on the relationship between economic growth and poverty.

\section{References}

Acemoglu, D., Johnson, S., \& Robinson, J., (2005), "Institutions as a Fundamental Cause of Long-Run Growth", In P. Aghion \& S. N. Durlauf (Eds.), Handbook of Economic Growth, 1, pp. 385-472.

Ahlburg, D. A., (1996), "Population Growth and Poverty", In D. A. Ahlburg, A. C. Kelley, \& K. O. Mason (Eds.), The Impact of Population Growth on Well-being in Developing Countries. Population Economics, Springer, Berlin, Heidelberg.

Almeida, I. I. A. F. d. (2020), The impact of institutions on economic growth across OECD, Master thesis, Universidade Do Porto.

Assadzadeh, A., \& Pourqoly, J. (2013). The relationship between foreign direct investment, institutional quality and poverty: case of MENA countries. Journal of Economics, Business and Management, 1(2), 161-165.

Asian Development Bank, (2002), "Poverty Reduction and the Role of Institutions in Developing Asia", Asian Development Bank.

Assane, D., \& Grammy, A., (2003), "Institutional framework and economic development: international evidence", Applied Economics, 35(17), 1811-1817.

Barro, R. J., (1991), "Economic Growth in a Cross Section of Countries", The Quarterly Journal of Economics, 106(2), 407-443.

Cuestas, J. C., \& Intartaglia, M. (2016), "Do institutions alleviate poverty? New empirical evidence", Economics Bulletin, 36, 145154 .

Dhrifi, A. (2013). A revisit of the "growth-inequality-poverty" relationship: the role of institutional quality. International journal of advances in management and economics, 2(1), 94-102.

Dollar, D., \& Kraay, A. (2002), "Growth is Good for the Poor". Development Research Group, the World Bank.

Easterly, W., \& Levine, R. (2003), "Tropics, Germs, and Crops: How Endowments Influence Economic Development", Journal of Monetary Economics, 50(1), 3-39.

Fayissa, B., \& Nsiah, C. (2010), "The Impact of Governance on Economic Growth: Further Evidence for Africa", Department of Economics and Finance.

Hajamini, M., \& Falahi, M. A. (2014). The nonlinear impact of government consumption expenditure on economic growth: Evidence from low and low-middle income countries. Cogent Economics \& Finance 2(1).

Hall, R. E., \& Jones, C. I. (1999), "Why Do Some Countries Produce So Much More Output Per Worker Than Others?", The Quarterly Journal of Economics, 114(1), 83-116. 
Hansen, B. E., (1999), "Threshold effects in non-dynamic panels: Estimation, testing, and inference", Journal of econometrics, 93 , 345-368.

http://iresearch.worldbank.org/PovcalNet/povOnDemand.aspx

http://info.worldbank.org/governance/wgi/

https://databank.worldbank.org/data/reports.aspx? source=WDI-Archives

https://www.rug.nl/ggdc/productivity/pwt/?lang=en

Huang, C.-J., \& Ho, Y.-H. (2017), "Governance and economic growth in Asia", The North American Journal of Economics and Finance, 39, 260-272.

Jindra, C., \& Vaz, A. (2019), "Good governance and multidimensional poverty: A comparative analysis of 71 countries", Governance, $32(4), 657-675$.

Kakwani, N., \& Pernia, E. M. (2000), "What is Pro-poor Growth?", Asian development review, 18(1), 1-16.

Kaufmann, D., \& Kraay, A. (2002), "Growth Without Governance". World Bank Policy Research Working Paper, $2928,1-59$.

Knack, S., \& Keefer, P. (1995), "Institutions and Economic Performance: Cross-Country Tests Using Alternative Institutional Indicators", Economics and Politics, 7(3), 207-228.

Kraay, A. (2006), "When is growth pro-poor? Evidence from a panel of countries", Journal of Development Economics, 80, $198-227$.

Law, C.-H., \& Soon, S.-V. (2020), "The impact of inflation on income inequality: the role of institutional quality", Applied Economics Letters, $27(21)$.

Liu, J., Tang, J., Zhou, B., \& Liang, Z. (2018). The effect of governance quality on economic growth: based on China's provincial panel data. Economies, 6(4), 2-23.

Lyubimov, I. (2017), "Income inequality revisited 60 years later: Piketty vs Kuznets", Russian Journal of Economics, 3, 42-53.

Mira, R., \& Hammadache, A. (2017). relationship between good governance and economic growth: A contribution to the institutional debate about state failure in developing countries. hal 01593290.

North, D. C. (1990), "Institutions, institutional change, and economic performance", Cambridge: Cambridge University Press.

Perera, L. D. H., \& Lee, G. H. Y. (2013), "Have economic growth and institutional quality contributed to poverty and inequality reduction in Asia?", Journal of Asian Economics, 27, 71-86.

Shirley, M. M. (2008), Institutions and Development, Edward Elgar Publishing.

Siddique, H., Shehzadi, I., \& Shaheen, A. (2016). The impact of governance and institutions on education and poverty alleviation: a panel study of SAARC economies. Science International Lahore, 28(2), 1431-1435

Tariq, N., Butt, A. R., \& Qasim, H. M. (2016), "Relationship between Institutions and Economic Growth", International Journal of Economics and Empirical Research, 4(7), 362-375.

Tebaldi, E., \& Mohan, R. (2010), "Institutions and Poverty", Journal of Development Studies, 46(6), 1047-1066.

This is an Open Access article distributed under the terms of the Creative Commons Attribution Licence 